\title{
Diagnostic and Therapeutic Approach to Acute Scaphoid Fractures
}

\section{Abordaje diagnóstico y terapéutico de las fracturas agudas de escafoides}

\author{
Fernando Polo Simón ${ }^{1,2,3}$ Belén García Medrano ${ }^{1,3}$ \\ ${ }^{1}$ Hand Surgery and Microsurgery Unit, Hospital Universitario HM \\ Montepríncipe, Boadilla del Monte, Madrid, Spain \\ 2 Mutua Universal, Madrid, Spain \\ 3 Orthopedic Surgery and Traumatology Service, Hospital \\ Universitario HM Montepríncipe, Boadilla del Monte, Madrid, Spain \\ Rev Iberam Cir Mano 2020;48:109-118.
}

\author{
Pedro J. Delgado Serrano ${ }^{1,3}$
}

\begin{abstract}
Keywords

- scaphoid fracture

- carpus

- wrist

- scaphoid

- carpal fractures
\end{abstract}

\section{Resumen}

Palabras clave

- fractura de escafoides

- carpo

- muñeca

- escafoides

- fracturas del carpo

- fracturas carpianas
The scaphoid is the carpal bone that most often fractures, accounting for up to $70 \%$ of carpal fractures and $11 \%$ of hand fractures. It is the second most common arm fracture, only surpassed by fractures of the distal radius. Despite being so common, these fractures can be difficult to diagnose and treat due to the anatomic and physiological particularities of the bone, including its precarious vascularization, its complex three-dimensional structure, and its ligament connections, which greatly contribute to the risk of complications such as malunion, pseudoarthrosis and avascular necrosis. Although there are many published studies on the treatment of these injuries, there is still controversy over what is the most suitable one for certain fracture types. The present article is a comprehensive and updated review of the literature. Combining strategies for clinical and radiological diagnosis, we propose a complete algorithm for the diagnosis of scaphoid fractures based on the varying availability of resources, and we also describe the most appropriate therapeutic approach for the different types of acute fractures of this bone.

El escafoides es el hueso del carpo que con mayor frecuencia se fractura; comprende hasta el $70 \%$ de las fracturas carpianas, y el $11 \%$ de las de la mano. Estas fracturas constituyen las segundas en frecuencia de todo el miembro superior, sólo superadas por las fracturas de la extremidad distal del radio. A pesar de ser tan frecuentes, pueden ser difíciles de diagnosticary de tratar debido a las particularidades anatómicas y fisiológicas del hueso, incluyendo su precaria vascularización, su compleja estructura tridimensional, y sus conexiones ligamentosas, que contribuyen al riesgo de complicaciones comola uniónen mala posición, la pseudoartrosis, yla necrosis avascular. Aunque existan numerosos estudios publicados sobre el tratamiento de estas lesiones, aún existe controversia sobre cuál es el más adecuado para determinados tipos de fractura. En este artículo se hace una revisión completa y actualizada de la literatura. Combinando estrategias de diagnóstico clínico y radiológico, se propone un algoritmo completo para el diagnóstico de las fracturas de escafoides en función de la distinta disponibilidad de medios, y se expone el abordaje terapéutico más apropiado para los distintos tipos de fracturas agudas de este hueso. received

April 1, 2020

accepted

July 27, 2020
DOI https://doi.org/

10.1055/s-0040-1718457. ISSN 1698-8396.
Copyright $\odot 2020$ Thieme Revinter

Publicações Ltda, Rio de Janeiro, Brazil
License terms

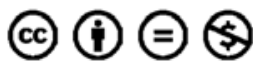




\section{Epidemiology}

The scaphoid is the most frequently fractured carpal bone, and is involved in up to $70 \%$ of carpal fractures, ${ }^{1}$ and $11 \%$ of hand fractures; scaphoid fractures are the second most common upper-limb fracture, only surpassed by distal-radial fractures. ${ }^{2}$ According to the recent literature, the incidence of this injury ranged from 22 to 141 cases per 100 thousand people per year. ${ }^{3}$ However, in a more recent publication using the US National Electronic Injury Surveillance System database, Van Tassel et $\mathrm{a}^{4}$ concluded that the current figure was much lower than what had been described in previous publications, with only 1.47 cases per 100 thousand people per year. Most of these fractures occur in young subjects, mostly in the age group between 20 and 29 years. ${ }^{4}$ In children, scaphoid fractures are much less common, representing only $3 \%$ of pediatric hand and wrist fractures. There is a clear predominance of scaphoid fractures in men (66.4\%). Nonetheless, recent studies observed an increased prevalence in women, probably due to their greater participation in organized sports. Although very common, these injuries may be difficult to diagnose and treat due to the anatomical and physiological characteristics of the scaphoid.

\section{Anatomy}

The scaphoid has a complex three-dimensional structure, described as an irregular, slightly twisted, S-curved ellipsoid. Its longitudinal axis is oriented at approximately $45^{\circ}$ to the longitudinal axis of the hand in both the sagittal and coronal planes. ${ }^{5}$ This complex morphology hampers the interpretation of the radiographs, the pattern of the fractures, and the evaluation of the displacement.

The scaphoid consists of four parts: tubercle, waist, proximal pole, and distal pole. Most authors, however, include the tubercle as part of the distal pole, without any specific distinction. Regarding the proximal pole, there is much discrepancy as to its initial point. The most accepted definition refers to the proximal $20 \%$ of the bone. ${ }^{6}$ Most fractures (approximately 70\%) occur at the scaphoid waist, with $20 \%$ at the distal pole, $5 \%$ at the tubercle, and the remaining $5 \%$ at the proximal pole. Certain properties of the bone structure may contribute to the higher incidence of waist fractures. In a cadaveric computed tomography (CT) study, Bindra ${ }^{7}$ found out that the scaphoid is denser at the proximal pole, in which the trabeculae are thicker and more firmly organized; the trabeculae are thinner, scarcer and dispersed at the scaphoid waist. ${ }^{2}$ Many publications have estimated that $70 \%$ to $80 \%$ of the total scaphoid covering surface is cartilaginous. This characteristic covering limits the entry area for blood vessels, resulting in a precarious vascularization. Furthermore, the small vessels that nourish the scaphoid are difficult to appreciate within the capsular structures, and there is a risk of unintentional injury during surgical interventions. As such, knowledge on the vascular anatomy of the scaphoid is critical. The dorsal scaphoid artery, a branch of the radial artery, is the most important vessel to supply blood to the scaphoid. The vascularization of the proximal $70 \%$ to $80 \%$ of the scaphoid depends on branches of this artery that pierce the bone in a narrow, non-articulated dorsal area, called dorsoradial ridge, and supply it retrogradely. This ridge separates the proximal and dorsal articular surfaces of the distal palmar scaphoid. The vascularization of the remaining $20 \%$ to $30 \%$ distal scaphoid is performed by small, direct palmar branches from the radial artery or superficial palmar arch that enter the scaphoid tubercle and the collateral circulation from the anterior interosseous artery. ${ }^{2,5,8,9}$ Some authors believe that vessels from scaphoid proximal and distal areas communicate within the bone, ${ }^{10}$ but others do not. ${ }^{9}$ Similarly, some authors speak about a potential third source of blood supply, inconsistent and thin, through the scapholunate ligament, ${ }^{11}$ while others vehemently question it. ${ }^{9}$ This unique vascularization predisposes the scaphoid, especially its proximal pole, to fracture-related avascular necrosis and pseudarthrosis.

The scaphoid connects the proximal and distal rows of the carpal bones, affecting the mobility of each row according to its position and functional demand. This effect results from multiple ligamentous attachments that play a crucial role in wrist stability and biomechanics. The present article does not intend to discuss specific details of the anatomy of the carpal ligament, but its knowledge is recommended for a better understanding of wrist biomechanics and scaphoid pathology. In displaced fractures, the proximal pole is extended due to its attachment to the lunate through the scapholunate ligament, while the distal fragment remains flexed due to its intimate union with the trapezius and the trapezoid through the triscaphe (scaphotrapeziotrapezoid) ligament, giving rise to the characteristic hump deformity of the scaphoid.

In conclusion, its poor vascularization, anatomy and ligamentous attachments greatly contribute to the risk of malunion and pseudoarthrosis. ${ }^{2}$

\section{Injury Mechanism}

Most scaphoid fractures occur after a fall with the extended wrist and radial deviation. ${ }^{12}$ The exact biomechanical mechanism has been discussed for decades. Todd, ${ }^{13}$ the first to study it, stated that it resulted from excessive stress, while Cobey and White ${ }^{14}$ argued that fractures are produced by excessive compression on the concave medial joint surface of the scaphoid by the capitate bone. In a cadaveric study, Frykman ${ }^{15}$ demonstrated that fractures are more likely to occur with wrist hyperextension and radial deviation, a finding later confirmed by Weber and Chao, ${ }^{16}$ who were able to recreate scaphoid fractures by load application on the radial area of the palm with the wrist in $95^{\circ}$ to $100^{\circ}$ of extension. ${ }^{17}$ Other fracture mechanisms described include direct blows or axial compression of the hand with the wrist in a neutral position.

\section{Diagnosis}

Despite the high frequency of scaphoid fractures, their diagnosis remains a great challenge. On the one hand, the 
complex three-dimensional structure of the scaphoid and the peculiar geometry of the fracture make them difficult to detect using plain radiographs. On the other hand, the fragile, precarious vascularization is an obstacle to consolidation and predisposes to complications such as delayed union, pseudoarthrosis and avascular necrosis. Late diagnosis and treatment increase the risk of these complications. Langhoff and Andersen ${ }^{18}$ showed that a treatment delay for 4 weeks increased the risk of nonunion to up to $40 \%$, while earlier diagnosis and treatment reduced the risk to $3 \%$. In addition to the short-term problems related to these complications (including pain, loss of strength and mobility), they result in osteoarthritis with a predictable degeneration pattern known as scaphoid nonunion advanced collapse (SNAC); SNAC can lead to greater functional limitation of the wrist, requiring salvage or palliative surgeries.

\section{Clinical Diagnosis}

At first, scaphoid fractures can easily go unnoticed, since many are imperceptible and the initial symptoms can be minimal, such as mild swelling and a slightly limitation in mobility. In these cases, if the patient reports a history of fall with the hand outstretched, an axial load on the wrist, or even a torsion, it is important to have a high index of suspicion not to miss an in situ or minimally-displaced fracture. In other cases, patients may present with more obvious signs, including edema, swelling in the anatomical snuff box, ecchymosis, limited wrist mobility, crepitation, and tenderness in the anatomic snuff box, scaphoid tubercle, and/or axial loading on the thumb.

Up to 25 different physical examination maneuvers have been described to identify scaphoid fractures. ${ }^{3}$ The most sensitive to diagnose acute injuries is pain during palpation of the anatomical snuff box, with figures ranging from $87 \%$ to $100 \% .{ }^{19}$ Other maneuvers with similar sensitivity are pain on tubercle palpation and axial compression of the thumb. Pain during thumb mobilization, although a widely used maneuver, is not so sensitive (with approximately $66 \%$ of sensitivity). Despite their high sensitivity, all of these maneuvers individually have very low specificity, with 9\%,30\%, 48\% and $69 \%$ respectively. ${ }^{20}$ However, it has been shown that their combined use within 24 hours of the injury increase specificity to $74 \%$, with $100 \%$ of sensitivity. In contrast, if only one maneuver is positive, the probability of fracture is very low, with a negative predictive value of $96 \% .^{21}$

In addition, Duckworth et $\mathrm{al}^{22}$ analyzed certain clinical and demographic variables and demonstrated that the positive predictive value increases to $94 \%$ if 4 variables are concurrently observed: male gender; sport-related injury; pain in the anatomical snuffbox during ulnar deviation of the wrist together with pain when performing a clamp with the thumb and index finger at the time of the injury; and persistence of pain on palpation of the scaphoid tubercle 2 weeks after the fracture.

Similarly, other studies have observed that some anatomical factors such as increased radial inclination, volar inclination, radius height, and a negative ulnar variance can be risk factors for scaphoid fractures. Therefore, in patients with a history of fall and support with the hand in extension, positive clinical signs along with radiological findings of negative ulnar variance and increased radius indices (radial tilt $>28.6^{\circ}$, volar tilt $>12.2^{\circ}$, and radial height $>14.8 \mathrm{~mm}$ ), there is an increased risk of scaphoid fracture, and the index of diagnostic suspicion must be higher. ${ }^{23}$

Although the literature disagrees on the predictive power of different signs and tests, all studies emphasize the need to always combine several maneuvers to increase the probability of detecting acute fractures.

\section{Imaging}

In a suspected scaphoid fracture, the initial diagnostic approach includes plain radiographs in posteroanterior and lateral views, in addition to an oblique view with $45^{\circ}$ pronation and a posteroanterior view with ulnar deviation (scaphoid projection). This latter view can help fracture visualization because the ulnar deviation of the wrist extends the scaphoid and distracts the unstable fragments; this is the best method to view scaphoid-waist fracture. The lateral view is good to detect tubercle and distal scaphoid injuries and to identify hump deformities by calculating the capitolunate, radiolunate, and scapholunate angles. ${ }^{3,24}$

An adequate radiographic study can detect fractures in $85 \%$ to $90 \%$ of cases. However, the initial radiographs can be negative, especially if the fractures are not displaced; the incidence of false-negative radiographs is up to $25 \%{ }^{25}$ Although subtle fractures are often more visible on plain radiographs after one or two weeks, they can remain radiologically hidden for up to six weeks. ${ }^{26}$ Considering this fact and the complications related to the delayed treatment of scaphoid fractures, we classically believed that all patients with clinical suspicion of scaphoid fracture, even those with negative radiographs, should be treated with wrist immobilization at presentation and reassessed both clinically and radiologically 7 to 10 days later for signs of bone displacement or resorption-enhancing evidence of fracture on radiographs. Although accepted in the clinical practice, this strategy has been shown to fail to detect up to $9 \%$ of scaphoid fractures, leading to a delay in their diagnosis and unnecessary immobilization in $57 \%$ to $80 \%$ of the patients with negative baseline radiographs. ${ }^{20}$ To avoid the consequences of both unnecessary and insufficient treatments, numerous studies recommend, whenever possible, advanced imaging tests such as magnetic resonance imaging (MRI) and computed tomography (CT) within the first week after the injury in patients with suspected occult scaphoid fractures. These tests have demonstrated much higher diagnostic sensitivity and specificity than plain radiographs, in addition to superior cost-effectiveness and better health outcomes than cast immobilization. ${ }^{20}$

The MRI is the gold standard test to diagnose occult scaphoid fractures, ${ }^{27}$ with sensitivity and specificity close to $100 \%$, and high interobserver reliability. It enables the detection of bone swelling a few hours after the injury, and it also has the advantage of enabling the identification of other concomitant wrist injuries both at the ligamentous and bone levels. ${ }^{17}$ According to some studies, the sensitivity of the CT 
to diagnose acute scaphoid fractures is similar to that of the MRI, but, as a disadvantage, it is contingent to technical factors. ${ }^{24}$ The CT is most useful in the acute setting, when the fracture is radiographically visible, due to its high degree of resolution; in addition, its multiplanar capacity make it the ideal test for surgical planning. The choice between MRI or CT to diagnose occult fractures is largely based on local availability soon after injury. However, if both are available, the MRI is the preferable test.

Recently published studies describe the usefulness of other imaging tests as alternatives to the MRI and CT. Ultrasound has been proposed to diagnose acute scaphoid fractures because it is a dynamic test and almost as available as radiographs. When the MRI and CT are not available, ultrasound may be more cost-effective than empirical immobilization. ${ }^{28}$ The main drawbacks of musculoskeletal ultrasound include its difficult performance and interpretation, the high operator-related contingency, and the inability to identify other carpal injuries or wrist fractures with initial clinical presentation similar to that of a scaphoid fracture. As such, when other methods are not available, ultrasound cannot be considered as reliable as a second imaging test to detect occult scaphoid fractures. ${ }^{24}$

A new technique using dual-energy computed tomography (DECT) has been developed, and shows promise in identifying acute scaphoid fractures (and other fractures). A version of this technique enables calcium subtraction, improving the visualization of bone marrow edema due to the increased image density. ${ }^{29}$ More studies are required to demonstrate its usefulness, but it is likely that its best applications are on patients who cannot undergo an MRI due to claustrophobia or for having an MRI-incompatible implanted device, or in places with no MRI available.

Recently, cone-beam computed tomography (CBCT) has witnessed a renaissance, with specific systems for hand and wrist applications. Although its role in evaluating soft tissues and deeper bone structures is very limited, studies have documented that the sensitivity of the CBCT in diagnosing scaphoid fractures is higher compared to that of radiographs, and that, at the wrist, the $\mathrm{CBCT}$ is just as good as conventional CT for diagnostic purposes. ${ }^{24}$ Its advantages include the lower cost, the fact that it can be easily positioned, and it is performed with the patient sitting down or standing up (instead of lying down with the arm in Superman position), and the lower exposure to ionizing radiation.

Considering all of the aforementioned information and combining clinical and radiological diagnostic strategies, we propose a complete algorithm to diagnose scaphoid fractures based on the availability of different imaging modalities (-Figure 1).

When a scaphoid fracture is clinically suspected based on combined test maneuvers and known demographic and anatomical risk factors, a proper series of x-rays is the first diagnostic test to be performed. If the results are negative, the most profitable strategy both from the socioeconomic and clinical outcome standpoint (more, if possible, in patients with high functional demand, such as athletes, manual workers, musicians etc.) is performing an MRI in the first hours after the trauma to rule out or confirm the fracture. If advanced imaging tests are not available, the risks posed by a delay in treatment result in an empirical immobilization of the wrist for 7 to 10 days (up to 2 weeks according to some studies) followed by a new clinical and radiological evaluation. If the clinical suspicion persists and the radiographs remain negative, the immobilization must be sustained, followed by a reevaluation in six weeks. After identifying a fracture, the attention must focus on its location and, most importantly, its displacement, which will determine the therapeutic plan. There is no real consensus on which measurements define a fracture as displaced or not and how to perform such measurements. In recent clinical trials, displacement is incompletely defined and inconsistently described, and mostly based on plain radiographic studies. Traditionally, a displaced fracture presents any of the following radiological criteria: scapholunate angle $>60^{\circ}$, a gap $\geq 1 \mathrm{~mm}$, or a radiolunate angle $>15^{\circ} .{ }^{3}$

Displacement is only detected on plain radiographs in $20 \%$ of scaphoid fractures; ${ }^{30}$ in addition, its magnitude is often much lower than the actual displacement observed during surgery. The most sensitive test for its correct assessment is $\mathrm{CT}$, which also provides information on comminution and joint incongruity. ${ }^{24}$ Therefore, a fracture detected on plain radiographs, especially if it is not displaced, must be confirmed with a CT scan. This test enables a more accurate evaluation of the displacement, a key factor in determining the conservative or surgical treatment of the fracture; in addition, it enables a good preoperative planning to define aspects such as the best approach, the appropriate osteosynthesis material etc.

\section{Classification}

In the last 70 years, a multitude of classifications for scaphoid fractures have been proposed based on their anatomical location, pattern or orientation, displacement, and even time since the injury, with considerable discrepancies among them. The most used classification systems ${ }^{31}$ are the Herbert or modified Herbert (-Figure 2), Russe (-Figure 3), and Cooney et al (also known as the Mayo classification).

In 1960, Russe ${ }^{32}$ classified scaphoid fractures into horizontal oblique, transverse, and vertical oblique patterns based on the orientation of the fracture line. Oblique vertical fractures are deemed the most unstable due to the shear forces crossing the fracture line, whereas horizontal oblique and transverse fractures are less subject to displacement due to compressive forces.

Years later, in 1980, Cooney et $\mathrm{al}^{33}$ (Mayo), distinguished stable and unstable fractures, considering the latter as those presenting displacement $>1 \mathrm{~mm}$, scapholunate angle $>60^{\circ}$, capitolunate angle $>15^{\circ}$, intrascaphoid lateral angle $>35^{\circ}$; in addition, the injuries were classified as comminuted fractures and lunate fracture-dislocations.

Even though the Russe and Cooney classification systems are very popular, the most used system is, undoubtedly, the one proposed in 1984 by Herbert and Fisher. ${ }^{34}$ This is an alphanumerical classification system with prognostic impact 


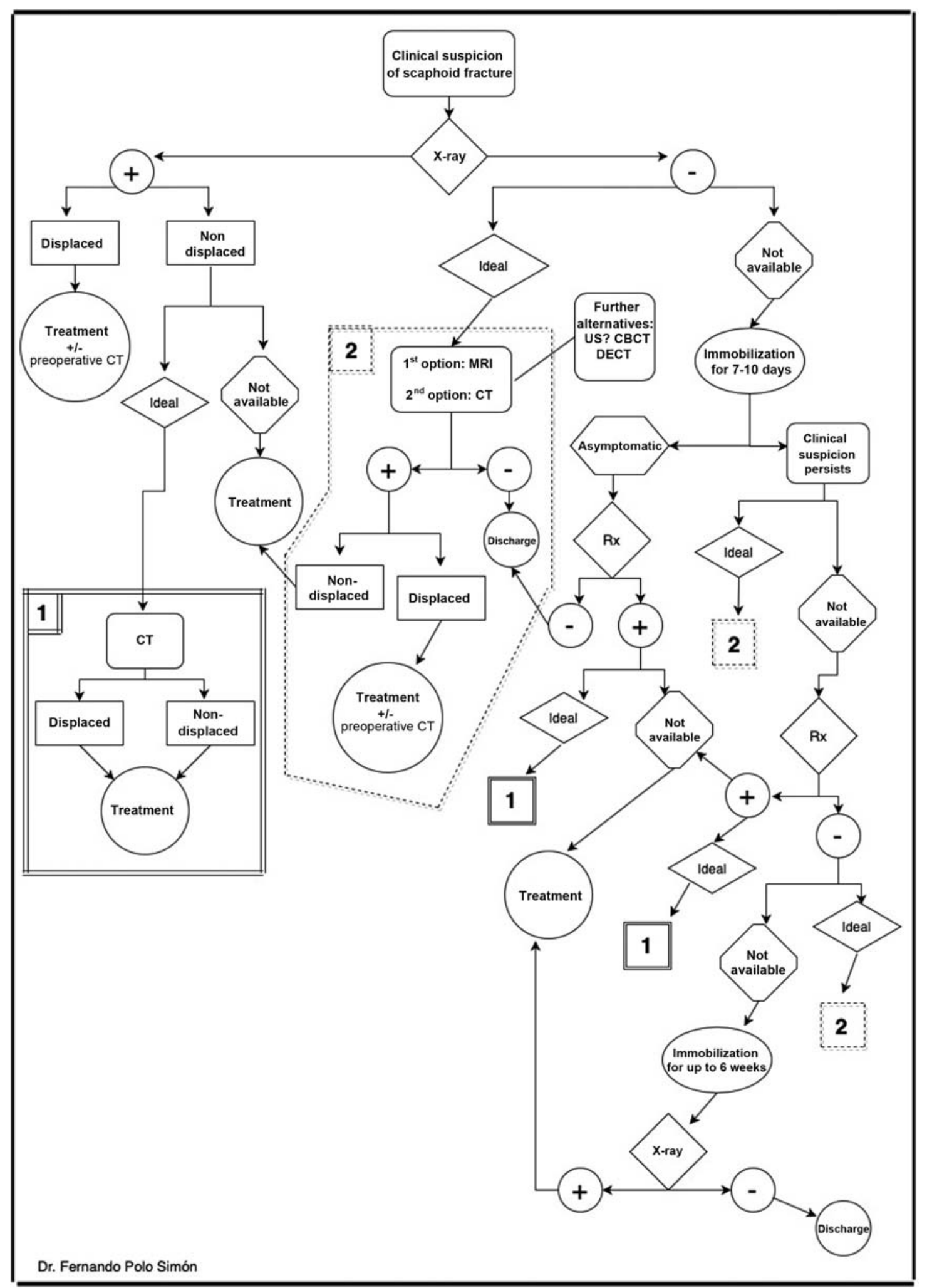

Fig. 1 Algorithm for the diagnosis of acute scaphoid fractures. (X-ray: plain X-ray; +: positive result; -: negative result; CT: computed tomography; MRI: magnetic resonance imaging; US: ultrasound; CBCT: cone-beam computed tomography; DECT: dual-energy computed tomography).

that considers the anatomical location of the fracture, its stability, and chronology. Based on these parameters, the fractures are divided into stable (type A), unstable (type B), delayed union (type C), and nonunion (type D). Type-A fractures include tubercle fractures (A1) and incomplete fractures of the scaphoid waist (A2). Type-B fractures include distal oblique fractures (B1), complete waist fractures (B2), proximal pole fractures (B3), trans-scapholunate fracture- 


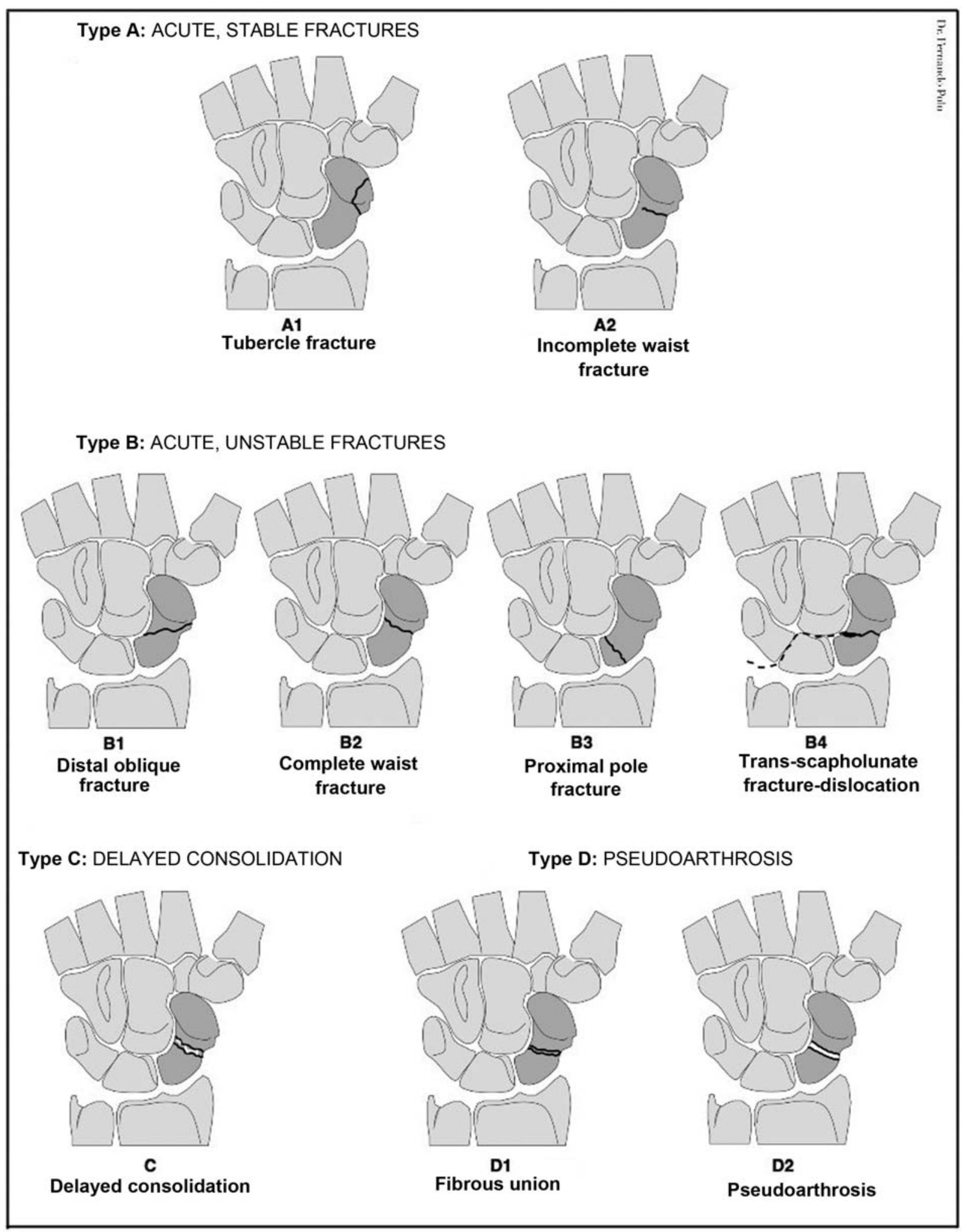

Fig. 2 Modified Hebert classification for scaphoid fractures (1996).

dislocations (B4), and comminuted fractures (B5). The 1996 modified Herbert classification omits B5 fractures. Type-C fractures are those with delayed union, and type-D fractures are established nonunion injuries, either fibrous (D1) or sclerotic (D2).
Finally, in 1988, Prosser et $\mathrm{al}^{35}$ observed that, up to that point, the literature had focused on waist fractures as they were the most frequent, paying little attention to the distal pole. Their work, although less relevant than the previous ones, proposed a classification for distal-pole fractures, 


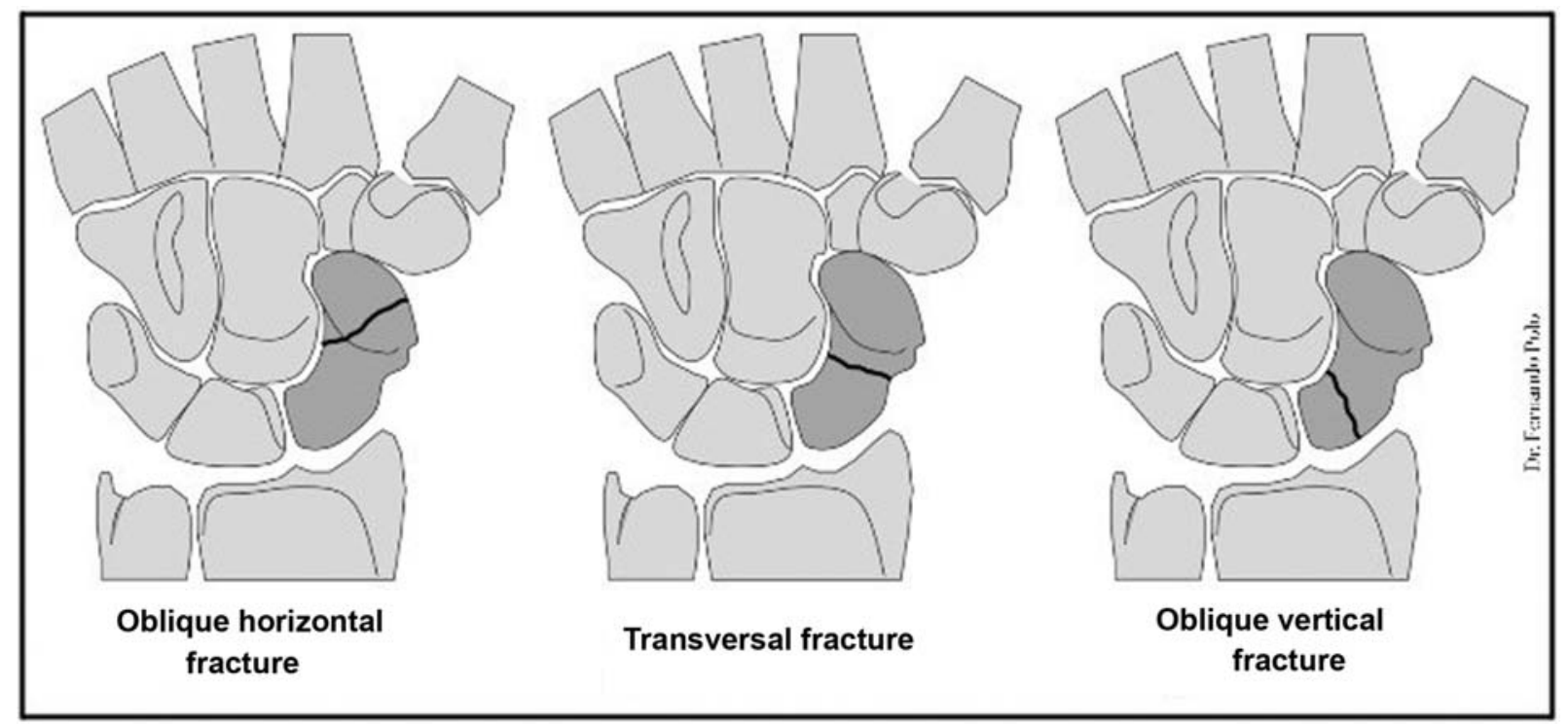

Fig. 3 Russe classification for scaphoid fractures (1960). 1. Oblique horizontal fracture 2. Transversal fracture 3. Oblique vertical fracture

distinguishing between tubercle fractures (type I), intraarticular compression fractures of the triscaphe (scaphotrapeziotrapezoid) joint (type II), with type IIA affecting the radial half of the distal scaphoid and type IIB affecting the ulnar half (a combination of types IIA and IIB results in a complex pattern, type IIC) and osteochondral fractures involving the medial border of the distal articular surface (type III).

The ultimate goal of all classifications is to differentiate stable and unstable fractures to determine the best treatment options for each of them. To date, all classifications have limited reliability, and there is no gold standard.

\section{Treatment}

When treating acute scaphoid fractures, the surgeon must consider several factors, including the time of diagnosis (early or late), fracture displacement, anatomical location, comminution, and the needs and expectations of the patient. Despite numerous publications on this subject, there is still controversy over which is the most appropriate therapeutic approach for selected types of fracture.

It is fully accepted that the best treatment for nondisplaced tubercle fractures is immobilization, with union rates close to $100 \%$ in a mean period of approximately 8 weeks. ${ }^{36}$ However, the best way to treat non-displaced fractures of the scaphoid distal pole and waist is still debated. Conservative treatment continues to be an appropriate, acceptable option for these fractures, since adequate immobilization can result in healing in 8 weeks in $90 \%$ of the cases. ${ }^{17,33}$ Nevertheless, some authors advocate the surgical treatment, which has been shown to reduce immobilization time, general costs, and delayed consolidation, in addition to resulting in better mobility outcomes and a faster return to work-related activities. ${ }^{33,37}$ In fact, some studies have observed that the surgical treatment is associated with a greater number of risks and complications compared to the conservative treatment, so the risks and long-term advantages of the surgical treatment of these stable fractures must be considered. ${ }^{17}$

For some time, another topic of debate has been whether or not a correct immobilization should include the thumb, if it should be limited only to the scaphoid wrist, or, alternatively, if it should be extended to the entire forearm, up to the elbow. Recent meta-analyzes and systematic reviews have shown that there is no benefit in immobilizing the forearm, elbow, or thumb. ${ }^{38}$ Therefore, correct immobilization must be distal to the elbow, with the wrist in a functional position, not including the thumb.

For the conservative treatment, the recommendation is to evaluate the healing status of the fracture by $\mathrm{CT}$, performing the first check-up 4 to 6 weeks after the beginning of the therapy. When consolidation is evident, the cast can be exchanged for a splint, followed by wrist rehabilitation. In contrast, if no consolidation is observed, the recommendation is to maintain immobilization and perform serial CT controls every 4 to 6 weeks until fracture union. ${ }^{20}$ When the $\mathrm{CT}$ is not available, it is important to add a clinical assessment to the plain radiographs. In this case, the first review can be delayed to 8 weeks. A fracture is considered clinically healed when the wrist can be mobilized with no risk of compromising its definitive union. ${ }^{39}$ Some studies have suggested that clinical healing occurs when the CT shows more than $50 \%$ of union of the fracture, ${ }^{3}$ although the accuracy of this figure has not been confirmed, and some works estimate that a higher percentage is required. ${ }^{40}$

Displaced, angled, comminuted, unstable fractures (see the Cooney classification) and proximal pole fractures undoubtedly require surgical treatment. Fixation techniques have not stopped evolving from the rudimentary use of Kirschner wires (now reserved for exceptional situations) to the modern biodegradable screws currently employed in some studies, including traditional headed screws, headless compression screws, locked plates and cannulated headless 
compression screws. The improvement in osteosynthesis materials has enabled the development of minimally-invasive techniques that improve the clinical outcomes and considerably reduce the aggressiveness and morbidity of the classical open approaches. The most frequently used fixation method is the subchondral placement of a cannulated headless compression screw along the longitudinal axis of the scaphoid. Non-displaced or minimally displaced fractures can be treated with this technique using percutaneous approaches with very good outcomes (- Figure 4). ${ }^{41}$ In cases of extreme comminution or subacute fractures with bone resorption, the use of one compression screw instead of two screws or a plate is becoming popular to increase rotational stability. Although several biomechanical studies support this option, there are still not enough clinical data comparing such techniques. $^{42}$

Among the percutaneous approaches, the volar and dorsal approaches are the most used. The volar percutaneous approach is usually recommended for osteosynthesis in non-displaced, minimally displaced, and displaced fractures that can be reduced by closed manipulation of the distal two thirds of the scaphoid. ${ }^{43}$ For non-displaced or minimally displaced proximal pole fractures, the percutaneous dorsal approach is recommended. Although there are discrepancies on the advantages of each of these percutaneous approaches, a recent meta-analysis has found no differences in the incidence of complications, nonunion, postoperative pain, or in functional outcomes and grip strength when comparing the volar and dorsal screw placements. Since no clear advantages have been demonstrated in favor of one or the other, a good surgeon must be familiar with both approaches. ${ }^{17}$ Regarding percutaneous osteosynthesis, technical developments are improving the precision of screw placement and minimizing surgical risks and complications. These include computer-assisted techniques, ${ }^{44}$ robot-assisted techniques, ${ }^{45}$ and custom-printed 3D templates for guide wires, ${ }^{46}$ which are still in a virtually experimental phase, but will be widely used in the future. In contrast, an already widespread technique with proven benefits is arthroscopy-assisted osteosynthesis, which enables visual confirmation of the fracture and its reduction, and correct positioning of the percutaneous screws while facilitating the diagnosis and treatment of associated ligament or joint injuries. ${ }^{47}$ Its main disadvantages are the greater technical difficulty and the additional equipment required.

Angulated, non-reducible, and/or comminuted fractures often require reduction and fixation using classic open approaches. Again, both the volar and dorsal approaches can be used. The volar approach has the theoretical advantage of preserving dorsal vascularization and providing good exposure of both the proximal and distal poles. Its main disadvantage is the need to divide the extrinsic carpal ligaments due to the risk of producing iatrogenic carpal instability. It is very important to spare these ligaments at wound closure. ${ }^{9,20}$ The open dorsal approach provides better exposure of the proximal two thirds of the scaphoid, enabling the visualization of the styloid and scaphoid radial fossae. However, the risk of damage to the vascularization of the dorsal scaphoid is higher, although no evidence suggests a higher rate of avascular necrosis compared to the volar approach. ${ }^{20}$ The advantages of this approach include better access to the central axis of the bone for the precise positioning of the compression screws and the avoidance of injury to the volar carpal ligaments without compromising the stability. ${ }^{2}$

As in conservatively-treated fractures, the healing of surgically-treated fractures must be followed up through CT scans. Very few studies evaluate the degree of union required to enable the unrestricted use of the wrist when the fracture is stabilized using osteosynthesis material. It is known that clinical healing is achieved more quickly when load transmission is shared with the implant. Cadaveric studies by Guss et $\mathrm{al}^{40}$ enable us to infer that the clinical healing of fractures treated with a compression screw is achieved with $50 \%$ of consolidation. Wrist arthroscopy can be used when the CT is not able to clearly demonstrate the
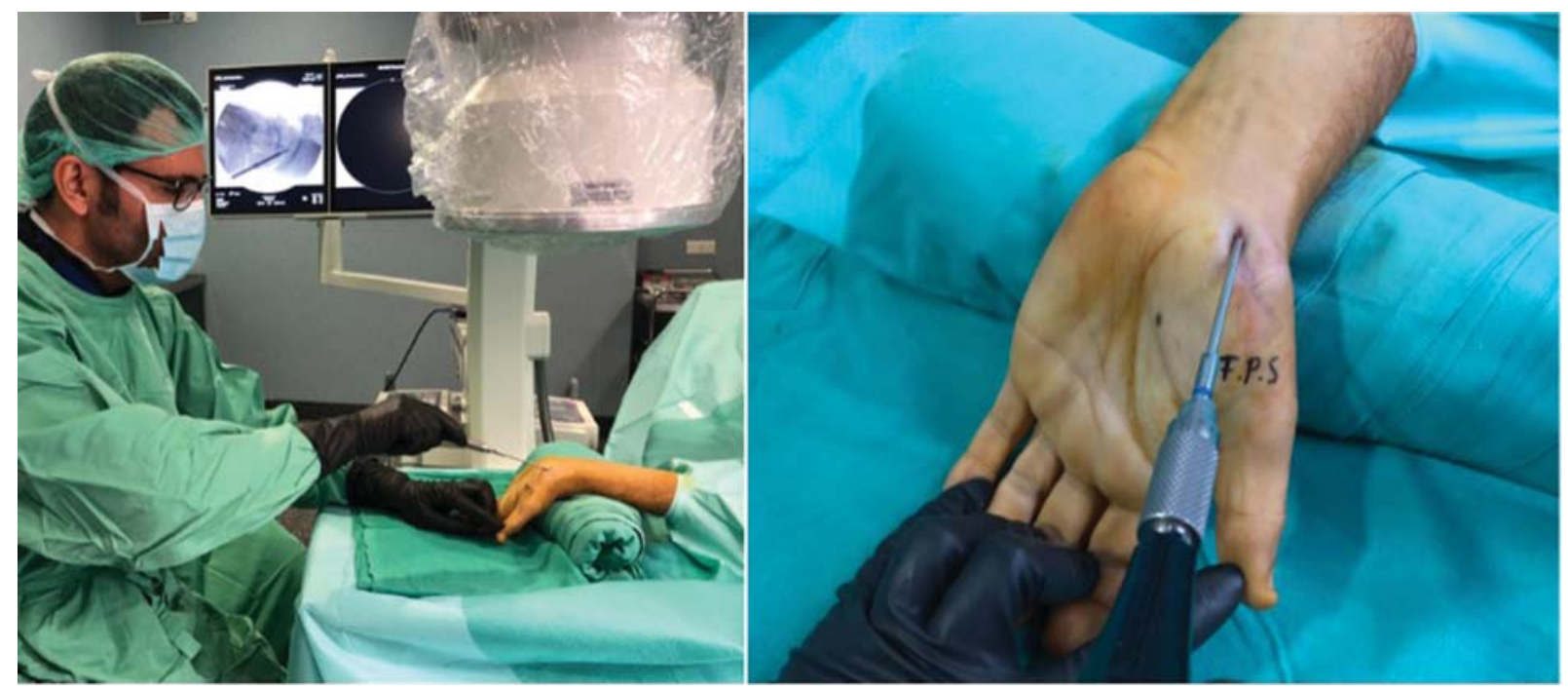

Fig. 4 Volar percutaneous osteosynthesis in a scaphoid fracture. 
status of the healing of the fracture or when there is doubt about its clinical stability.

\section{Complications}

The most frequent and fearsome complications of these fractures usually result from inadequate treatment due to diagnostic delays and the incorrect assessment of instability and/or displacement of the fracture, leading to pseudoarthrosis, osteonecrosis, posttraumatic osteoarthritis and even rupture of the flexor and extensor tendons. ${ }^{3}$ The rate of nonunion in conservatively treated scaphoid fractures ranges from $5 \%$ to $10 \%$, with higher figures in proximal pole fractures.

Delayed healing of the fracture (more than 16 weeks) after proper initial fixation is rare. In this case, avascular necrosis or implant loosening must be suspected. Avascular necrosis occurs in $13 \%$ to $50 \%$ of all scaphoid fractures, with a higher incidence in more proximal fractures. Some studies even reported up to $100 \%$ in fractures involving the proximal fifth of the bone. ${ }^{3,33,34}$ Complications can occur with both the conservative and surgical treatments. Complications involving the cast immobilization include disuse atrophy, stiffness, osteoporosis, complex regional pain syndrome, and transient compressive neuropathies. The most important complications from the surgical treatment are mispositioning of the screw (with no proper fracture stabilization or with the screw protruding from the surfaces of the proximal or distal joints), osteonecrosis, misaligned union, pseudarthrosis, and need for implant removal. The rate of surgical complications ranges from $0 \%$ to $29 \%$. In most studies, it is low, ${ }^{3}$ although there is greater risk with open approaches.

\section{Conclusions}

Scaphoid fractures are the most frequent among carpal fractures, but they can be difficult to diagnose and treat due to anatomical and physiological characteristics of the scaphoid. The present article proposes a complete algorithm to diagnose scaphoid fractures based on the different availability of imaging modalities.

When suspecting a scaphoid fracture, the initial diagnostic approach must include plain radiographs. Furthermore, all studies emphasize the need to always combine several physical examination maneuvers. The initial radiographs may be negative, so, whenever possible, the patients with suspected occult scaphoid fractures must be submitted to advanced imaging tests, such as MRI or CT, within the first week after the injury. The best treatment for non-displaced tubercle fractures is immobilization, with union rates close to $100 \%$ in a mean time of approximately 8 weeks. The conservative treatment continues to be an appropriate, acceptable option for non-displaced fractures at the rest of the distal pole and the scaphoid waist. However, some authors advocate the surgical treatment, which has been shown to reduce the time and costs of immobilization, in addition to resulting in better clinical outcomes and quicker return to work-related activities. Displaced, angled, commi- nuted, unstable and proximal pole fractures must be treated surgically. The surgical technique and approach of choice will depend on the location, trajectory and comminution of the fracture, among other factors.

\section{References}

1 Papp S. Carpal bone fractures. Hand Clin 2010;26(01):119-127

2 Sendher R, Ladd AL. The scaphoid. Orthop Clin North Am 2013;44 (01):107-120

3 Tait MA, Bracey JW, Gaston RG. Acute scaphoid fractures. A critical analysis review. JBJS Rev 2016;4(09):e3

4 Van Tassel DC, Owens BD, Wolf JM. Incidence estimates and demographics of scaphoid fracture in the U.S. population. J Hand Surg Am 2010;35(08):1242-1245

5 Langer MF, Unglaub F, Breiter S, Ueberberg J, Wieskötter B, Oeckenpöhler S. [Anatomy and pathobiomechanics of the scaphoid]. Unfallchirurg 2019;122(03):170-181

6 Dias J, Kantharuban S. Treatment of scaphoid fractures. Hand Clin 2017;33(03):501-509

7 Bindra RR. Scaphoid density by CT scan. Bucharest (Hungary): IFSSH; 2004

8 Garcia-Elias M, Cooney WP, An KN, Linscheid RL, Chao EY. Wrist kinematics after limited intercarpal arthrodesis. J Hand Surg Am 1989;14(05):791-799

9 Gelberman RH, Menon J. The vascularity of the scaphoid bone. J Hand Surg Am 1980;5(05):508-513

10 Oehmke MJ, Podranski T, Klaus R, et al. The blood supply of the scaphoid bone. J Hand Surg Eur Vol 2009;34(03):351-357

11 Herbert TJ, Lanzetta M. Idiopathic avascular necrosis of the scaphoid. J Hand Surg [Br] 1994;19(02):174-182

12 Mayfield JK. Mechanism of carpal injuries. Clin Orthop Relat Res 1980;(149):45-54

13 Todd AH. Fractures of the carpal scaphoid. Br J Surg 1921;9:7-26

14 Cobey MC, White RK. An operation for non-union of fractures of the carpal navicular. J Bone Joint Surg Am 1946;28(04):757-764

15 Frykman G. Fracture of the distal radius including sequelaeshoulder-hand-finger syndrome, disturbance in the distal radio-ulnar joint and impairment of nerve function. A clinical and experimental study. Acta Orthop Scand 1967(Suppl 108):3+

16 Weber ER, Chao EYS. An experimental approach to the mechanism of scaphoid waist fractures. J Hand Surg Am 1978;3(02):142-148

17 Sabbagh MD, Morsy M, Moran SL. Diagnosis and management of acute scaphoid fractures. Hand Clin 2019;35(03):259-269

18 Langhoff O, Andersen JL. Consequences of late immobilization of scaphoid fractures. J Hand Surg [Br] 1988;13(01):77-79

19 Mallee WH, Henny EP, van Dijk CN, Kamminga SP, van Enst WA, Kloen P. Clinical diagnostic evaluation for scaphoid fractures: a systematic review and meta-analysis. J Hand Surg Am 2014;39 (09):1683-1691.e2

20 Suh N, Grewal R. Controversies and best practices for acute scaphoid fracture management. J Hand Surg Eur Vol 2018;43 (01):4-12

21 Parvizi J, Wayman J, Kelly P, Moran CG. Combining the clinical signs improves diagnosis of scaphoid fractures. A prospective study with follow-up. J Hand Surg [Br] 1998;23(03):324-327

22 Duckworth AD, Buijze GA, Moran M, et al. Predictors of fracture following suspected injury to the scaphoid. J Bone Joint Surg $\mathrm{Br}$ 2012;94(07):961-968

23 Turan A, Kose O, Aktan C, Unal M, Acar B, Sindel M. Radiographic analysis of anatomic risk factors for scaphoid fractures; A casecontrol study. Clin Imaging 2018;51:341-346

24 Amrami KK, Frick MA, Matsumoto JM. Imaging for acute and chronic scaphoid fractures. Hand Clin 2019;35(03):241-257

25 Leslie IJ, Dickson RA. The fractured carpal scaphoid. Natural history and factors influencing outcome. J Bone Joint Surg $\mathrm{Br}$ 1981;63-B(02):225-230 
26 Lenoir H, Coulet B, Lazerges C, Mares O, Croutzet P, Chammas M. Idiopathic avascular necrosis of the scaphoid: 10 new cases and a review of the literature. Indications for Preiser's disease. Orthop Traumatol Surg Res 2012;98(04):390-397

27 Murthy NS. The role of magnetic resonance imaging in scaphoid fractures. J Hand Surg Am 2013;38(10):2047-2054

28 Kwee RM, Kwee TC. Ultrasound for diagnosing radiographically occult scaphoid fracture. Skeletal Radiol 2018;47(09):1205-1212

29 Pache G, Krauss B, Strohm P, et al. Dual-energy CT virtual noncalcium technique: detecting posttraumatic bone marrow lesions-feasibility study. Radiology 2010;256(02):617-624

30 Fowler JR, Hughes TB. Scaphoid fractures. Clin Sports Med 2015; 34(01):37-50

31 Ten Berg PW, Drijkoningen T, Strackee SD, Buijze GA. Classifications of acute scaphoid fractures: a systematic literature review. J Wrist Surg 2016;5(02):152-159

32 Russe O. Fracture of the carpal navicular. Diagnosis, non-operative treatment, and operative treatment. J Bone Joint Surg Am 1960;42-A:759-768

33 Cooney WP, Dobyns JH, Linscheid RL. Fractures of the scaphoid: a rational approach to management. Clin Orthop Relat Res 1980; (149):90-97

34 Herbert TJ, Fisher WE. Management of the fractured scaphoid using a new bone screw. J Bone Joint Surg Br 1984;66(01):114-123

35 Prosser AJ, Brenkel IJ, Irvine GB. Articular fractures of the distal scaphoid. J Hand Surg [Br] 1988;13(01):87-91

36 Grewal R, Suh N, Macdermid JC. Use of computed tomography to predict union and time to union in acute scaphoid fractures treated nonoperatively. J Hand Surg Am 2013;38(05):872-877

37 Al-Ajmi TA, Al-Faryan KH, Al-Kanaan NF, et al. A systematic review and meta-analysis of randomized controlled trials com- paring surgical versus conservative treatments for acute undisplaced or minimally-displaced scaphoid fractures. Clin Orthop Surg 2018;10(01):64-73

38 Doornberg JN, Buijze GA, Ham SJ, Ring D, Bhandari M, Poolman RW. Nonoperative treatment for acute scaphoid fractures: a systematic review and meta-analysis of randomized controlled trials. J Trauma 2011;71(04):1073-1081

39 Dias JJ. Definition of union after acute fracture and surgery for fracture nonunion of the scaphoid. J Hand Surg [Br] 2001;26(04): 321-325

40 Guss MS, Mitgang JT, Sapienza A. Scaphoid healing required for unrestrited activity: a biomechanical cadaver model. J Hand Surg Am 2018;43(02):134-138

41 Ram AN, Chung KC. Evidence-based management of acute nondisplaced scaphoid waist fractures. J Hand Surg Am 2009;34(04): 735-738

42 Jernigan EW, Morse KW, Carlson MG. Managing the athlete with scaphoid fracture. Hand Clin 2019;35(03):365-371

43 Gupta V, Rijal L, Jawed A. Managing scaphoid fractures. How we do it? J Clin Orthop Trauma 2013;4(01):3-10

44 Xiao ZR, Xiong G. Computer-assisted surgery for scaphoid fracture. Curr Med Sci 2018;38(06):941-948

45 Liu B, Wu F, Chen S, Jiang X, Tian W. Robot-assisted percutaneous scaphoid fracture fixation: a report of ten patients. J Hand Surg Eur Vol 2019;44(07):685-691

46 Salabi V, Rigoulot G, Sautet A, Cambon-Binder A. Three-dimensional-printed patient-specific Kirschner-wire guide for percutaneous fixation of undisplaced scaphoid fractures: a cadaveric study. J Hand Surg Eur Vol 2019;44(07):692-696

47 Geissler WB, Hammit MD. Arthroscopic aided fixation of scaphoid fractures. Hand Clin 2001;17(04):575-588, viii 